\title{
Effect of high-intensity interval training on treadmill exercise with changes in inclination on serum IL-6 levels in overweight/obese men
}

\author{
Daud Suryaningrat Turupadang ${ }^{1}$, Nuniek Nugraheni ${ }^{2}$, Damayanti Tinduh ${ }^{3 *}$, \\ Sony Wibisono ${ }^{4}$ \\ ${ }^{123}$ Department of Physical Medicine and Rehabilitation, Faculty of Medicine Universitas Airlangga/ Dr. Soetomo \\ Academic General Hospital, Surabaya, Indonesia \\ ${ }^{4}$ Department of Physical Medicine and Rehabilitation, Internal Medicine, Faculty of Medicine Universitas Airlangga \\ Corresponding author: Damayanti Tinduh \\ Email corresponding author: damayanti.tinduh@fk.unair.ac.id
}

\begin{abstract}
Background: Obesity and overweight conditions showed an increase in plasma interleukin-6 (IL6) concentrations associated with fat mass. Adipocytes produce the proinflammatory cytokine IL6 , which plays a pathogenic role in chronic disease. Increased levels of inflammatory cytokines continuously cause cardiovascular complications, metabolic problems, and even death. Physical exercise is one of the treatments for overweight and obesity that, if done regularly, can reduce the basal value of IL-6. High Intensity Interval Training (HIIT) is a form of high-intensity exercise that recruits larger muscles than moderate-intensity training so that it will have an effect on increasing levels of IL-6 acute response and can reduce basal IL-6 levels with a relatively shorter duration of exercise.

Objective: To analyze changes in basal serum IL-6 levels and acute responses before and after high-intensity interval training treadmill exercise with changes in inclination for four weeks in overweight or obese men.

Methods: The study was conducted from October to November 2020. Twenty-two overweight or obese men were randomly assigned to the treatment group and the control group. The group did HIIT using a treadmill with incline changes for 30 minutes for 4 weeks. The control group did not receive intervention and was educated to continue physical activity as usual. Measurement of IL-6 levels was carried out before and after treatment.

Results: The administration of the HIIT intervention for 4 weeks can reduce basal IL-6 levels. There was a significant decrease $(p=0.04)$ in the basal IL-6 after the intervention. Likewise, the comparative analysis between the two groups showed a significant difference in reduction after the intervention $(\mathrm{p}=0.000)$. The delta glass effect size obtained a value of 0.866728 , which indicates a large effect.
\end{abstract}

Conclusion: HIIT can be proposed as an exercise therapy option to reduce basal IL-6 levels in overweight or obese men.

Keywords: high intensity interval training (HIIT); overweight; obesity; serum IL-6; treadmills; Physical Medicine and Rehabilitation; Indonesia

\section{Introduction}

In obese subjects, the plasma concentration of IL-6 was found to increase, which was associated with fat mass. TNF- and IL-6, which are produced by adipocyte tissue, play a pathogenic role in chronic inflammatory diseases (Kershaw and Flier, 2004).

Interleukin-6 (IL-6) was the first cytokine to be introduced as a myokine which is increased during exercise, especially in conditions of low muscle glycogen (acute response). In contrast to the chronic increase in IL-6, this acute increase in IL-6 actually has an anti-inflammatory effect, has a good impact on metabolic function, inhibits TNF-and IL-1, plays a role in cell regeneration, inhibits cell death, and induces lipolysis. Therefore, measurement of IL-6 levels needs to be carried out in a basal state and also during an acute response (Leggate, 2010). 
Continuously increasing levels of inflammatory cytokines in the form of chronic low-grade systemic inflammation will cause cardiovascular, metabolic, and even death complications (Petersen and Pedersen, 2005; Thiruvoipati et al., 2015). Therefore, it is very important to measure basal levels of IL-6, which serves as a predictor of complications from obesity (Tanaka et al., 2014; Qu et al., 2014).

Physical exercise is one of the treatments for overweight and obesity that, if done regularly, can reduce the basal value of IL-6. High Intensity Interval Training (HIIT) is a form of highintensity exercise that recruits larger muscles than moderate-intensity training so that it will have an effect on increasing levels of IL-6 acute response with a relatively shorter duration of exercise (Ilyas, 2009; Leggate, 2010; Kilpatrick, 2014; Polen and Joshi, 2014; Cassidy, 2016; Eaton, 2017; Elias, 2019).

Until now, research on IL-6 levels, both basal and acute response to HIIT, is still very minimal in Indonesia and only assesses basal IL-6 levels without assessing the acute response. Based on the above phenomenon, the researchers wanted to examine the effects of HIIT exercise with changes in inclination on IL-6 levels in overweight or obese men, both at basal levels and acute responses.

\section{Methods}

This research was conducted at Physical Medicine and Rehabilitation outpatient clinic Dr. Soetomo Academic General Hospital in October-November 2020. Twenty-two overweight or obese men who met the study criteria were randomly assigned to the treatment group and the control group. The group did HIIT using a treadmill (rest heart rate $+80-90 \%$ reserve heart rate) with incline changes for 30 minutes (starting with warming up and ending with cooling down, 5 minutes each) 3 times a week for 4 weeks. The control group did not receive intervention and was educated to continue physical activity as usual. Measurement of IL-6 levels was carried out before the first exercise (basal) and 30 minutes after the first exercise (acute response). Then, after 4 weeks of treatment, IL-6 levels were examined before the last exercise (basal) and 30 minutes after the last exercise (acute response).

This research has obtained an ethical certificate from the ethics committee of Dr. Soetomo Academic General Hospital Surabaya with the code number 2003/KEPK/V/2020. All data were analyzed using SPSS version 26.

\section{Results}

A total of 21 research subjects were able to complete the study, and 1 research subject could not complete the study because he refused to take a second IL-6 examination without giving reasons.

Table 1. Basic characteristics and normality test of subjects

\begin{tabular}{lcccc}
\hline Variable & $\begin{array}{c}\text { Intervention group } \\
(\mathbf{n}=\mathbf{1 1})\end{array}$ & p-value & $\begin{array}{c}\text { Control group } \\
(\mathbf{n}=\mathbf{1 0})\end{array}$ & p-value \\
\hline Age (Year) & $30,36 \pm 2,58$ & $0,775^{*}$ & $34,40+2,91$ & $0,051^{*}$ \\
BMI (Kg/ cm $\left.{ }^{2}\right)$ & $28,62 \pm 3,33$ & $0,259^{*}$ & $27,26 \pm 2,70$ & $0,116^{*}$ \\
Early basal IL-6 & $54,20 \pm 116,73$ & 0,000 & $39,54 \pm 43,55$ & 0,044 \\
Early acute response IL-6 & $6,25 \pm 6,16$ & 0,003 & - & - \\
\hline
\end{tabular}

Normality test using Shapiro-Wilk.

* p-value indicates the probability or significance level of the initial data, significant or normally distributed data when $\mathrm{p}>0.05$

Table 1 shows the number of subjects analyzed in each group. Normal distribution was shown in the variables of age and BMI. Abnormal distribution was found in basal IL-6 and acute response IL-6 before intervention

Table 2. Basic characteristics and homogeneity test of subjects 


\begin{tabular}{lccc} 
Variable & $\begin{array}{c}\text { Intervention group } \\
(\mathbf{n}=\mathbf{1 1})\end{array}$ & $\begin{array}{c}\text { Control group } \\
(\mathbf{n}=\mathbf{1 0})\end{array}$ & p-value \\
\hline Age (Year) & $30,36 \pm 2,58$ & $34,40+2,91$ & $0,572^{*}$ \\
BMI (Kg/ cm2) & $28,62 \pm 3,33$ & $27,26 \pm 2,70$ & $0,737^{*}$ \\
Basal IL-6 & $54,20 \pm 116,73$ & $39,54 \pm 43,55$ & $0,310^{*}$
\end{tabular}

Homogeneity test using Levene's test

$*$ p-value indicates the probability or significance level of the initial data, homogeneous data when $\mathrm{p}>0.05$

Table 2 shows that the two groups obtained homogeneous data on age, BMI, and basaI L-6 before intervention.

Table 3. Comparison of mean basal serum IL-6 levels before and after intervention

\begin{tabular}{lccc}
\hline & Early basal IL-6 & Late basal IL-6 & p-value \\
\hline $\begin{array}{l}\text { Intervention group } \\
(\mathrm{n}=11)\end{array}$ & $54,20 \pm 116,73$ & $3,55 \pm 2,24$ & $0,04 *$ \\
$\begin{array}{l}\text { Control group } \\
(\mathrm{n}=10)\end{array}$ & $39,54 \pm 43,55$ & $181,46 \pm 205,27$ & 0,093 \\
\hline
\end{tabular}

Wilcoxon test $*$ Significant when p-value $<0,05$

Table 3 shows a significant decrease in basal IL-6 before and after intervention, while in the control group there was no significant difference.

Table 4. Comparison of mean acute response serum IL- 6 levels before and after intervention

\begin{tabular}{lccc}
\hline & $\begin{array}{c}\text { Early acute response } \\
\text { IL-6 }\end{array}$ & $\begin{array}{c}\text { Late acute response } \\
\text { IL-6 }\end{array}$ & p-value \\
\hline $\begin{array}{l}\text { Intervention group } \\
(\mathrm{n}=11)\end{array}$ & $6,25 \pm 6,15$ & $164,67 \pm 243,60$ & $0,006^{*}$ \\
\hline
\end{tabular}

Wilcoxon test $*$ Significant when $\mathrm{p}$-value $<0,05$

Table 4 shows a significant increase in acute response IL-6 in the intervention group after intervention.

Table 5. Comparison of mean basal IL-6 levels before intervention between the two groups and basal IL-6 levels after intervention between the two groups

\begin{tabular}{lccc}
\hline Variable & $\begin{array}{c}\text { Intervention group } \\
(\mathbf{n = 1 1})\end{array}$ & $\begin{array}{c}\text { Control group } \\
(\mathbf{n}=\mathbf{1 0})\end{array}$ & p-value \\
\hline Early basal IL-6 & $54,20 \pm 116,73$ & $39,54 \pm 43,55$ & 0,310 \\
Late basal IL-6 & $3,55 \pm 2,24$ & $181,46 \pm 205,27$ & $0,000^{*}$ \\
\hline
\end{tabular}

Mann Whitney test. *Significant when p-value $<0,05$

Table 5 shows a significant decrease of basal IL-6 after intervention 
Table 6. Effect size basal serum IL-6 levels after intervention

\begin{tabular}{lcccc}
\hline Variable & Intervention group & Control group & $\begin{array}{c}\text { Standard deviation } \\
\text { Comparison }\end{array}$ & Delta Glass \\
\hline Basal IL-6 & 3,545 & 181.445 & 205.266 & -0.866728 \\
\hline
\end{tabular}

Effect size threshold; 0,20: small; 0,50: medium; 0,80: large; 1,3: very large

Assessment of effect size on basal IL-6 levels in the intervention group compared to the control group obtained a large effect with a value of -0.866728 .

Table 7. Comparison of the mean values of basal and acute response serum IL-6 levels

\begin{tabular}{lccc}
\hline & Basal IL-6 & Acute response IL-6 & p-value \\
\hline Before intervention & $54,20 \pm 116,73$ & $6,25 \pm 6,15$ & $0,026^{*}$ \\
After intervention & $3,55 \pm 2,24$ & $164,67 \pm 243,60$ & $0,04^{*}$ \\
\hline
\end{tabular}

Wilcoxon test . *Significant when p-value $<0,05$

In the intervention group, there was a significant decrease in acute response IL-6 compared to the basal IL- 6 before intervention, and there was a significant increase in acute response IL-6 compared to the basal IL-6 after intervention.

\section{Discussion}

In this study, the basal IL-6 level after the intervention decreased significantly, as well as a significant decrease when compared to the basal IL-6 level in the control group. Calculation of the value of the effect size obtained a value indicating the presence of a large effect, with a minus value indicating a decreasing effect, so it can be concluded that the administration of HIIT intervention for 4 weeks can reduce basal IL- 6 levels. This is in accordance with the literature which states that the effect of physical exercise when done regularly can reduce the basal value of IL-6 (chronic adaptation to exercise). This decrease depends on the intensity and duration of exercise and a person's level of fitness. Individuals who do regular physical exercise show lower IL-6 basal levels than sedentary individuals (Monteiro-Junior et al., 2018; Gomez-Rubio and Trapero, 2019).

The acute response IL-6 level increased significantly when compared to the basal IL-6 level after intervention. This is in accordance with the literature, which explains that the acute response due to skeletal muscle contraction during physical exercise will trigger the synthesis and release of IL-6 in the circulation as an anti-inflammatory, so that IL-6 levels will increase during physical exercise after 30 minutes and reach their highest concentration at the end of the exercise. (GomezRubio and Trapero, 2019).

Acute response IL-6 levels in the treatment group before intervention decreased significantly when compared to basal IL-6 levels. This is not in accordance with the literature, which says that acute response IL-6 after 30 minutes of physical exercise will increase up to five times, even up to a hundred times, and reach a peak at the end of the exercise, after which it will decrease rapidly to pre-exercise levels (Pedersen, 2017). In this study, it is possible that there has been an increase in acute response IL-6 levels in untrained overweight/obese subjects immediately after exercise but then a rapid decrease in acute response IL- 6 levels ( $<30$ minutes) so that the increase was not seen because the examination of IL-6 levels was carried out 30 minutes after the exercise was completed due to the limitations of the study, it was not possible to carry out laboratory tests immediately after exercise. This finding is a separate phenomenon that perhaps further research can be carried out on acute response IL-6 levels after doing HIIT in overweight or obese subjects who have not been trained to see whether there is a faster decline and can also be compared with trained overweight or obese subjects where sampling was carried out at least three times, namely before exercise, immediately after exercise, and 30 minutes after exercise. 
Another thing that could explain why there was a decrease in acute response IL-6 levels at the beginning of this study was the limitations of the investigators' ability to control the subject's diet before exercise. From the literature, it is stated that there are several factors that can prevent an increase in IL-6 levels in an acute response during exercise, namely taking antioxidant supplements such as vitamin $\mathrm{C}$ and vitamin $\mathrm{E}$, taking NSAIDs (indomethacin), and consuming carbohydrates just before exercise (Fischer, 2006). This research was conducted during the Covid19 pandemic, so it is possible for most of the samples to have taken antioxidant supplements. Likewise, the level of IL-6 in the late acute response increased significantly when compared to the IL-6 in the early acute response. This is not in accordance with the literature which states that after regular physical exercise, the level of IL-6 in the acute response will decrease due to adaptation from Muscles that initially have a glycogen deficit will store more glycogen and will use more fat as an energy source during physical exercise, while this glycogen deficit muscle is thought to stimulate the formation of IL-6 (Pedersen \& Febbraio, 2008). In conditions of low muscle glycogen, the rate of IL- 6 transcription is faster and relatively more, but the opposite occurs when the muscle glycogen content is high. Thus, the acute plasma IL-6 response should be lower in trained subjects than in untrained subjects (Pedersen \& Febbraio, 2008), but in this study, the final acute response IL-6 level was increased. This could be due to the fact that the length of the study was not sufficient to induce muscle adaptation in research subjects, where in several studies conducted on adult subjects, exercise was carried out for at least 12 weeks (Gomez-Rubio and Trapero, 2019). In addition, it is possible that the decrease in acute response IL-6 levels in untrained subjects was faster than in trained subjects, so that sampling should be carried out immediately after exercise or end of exercise and 30 minutes after exercise is completed.

\section{Conclusion}

There was a decrease in basal serum IL-6 levels in overweight/obese men who received HIIT treadmill exercise with changes in inclination for 4 weeks. There was no decrease in acute response serum IL-6 levels in overweight/obese men receiving HIIT treadmill exercise with a change in inclination for 4 weeks.

\section{References}

Leggate, M., Nowel, M., Jones, S., and Nimmo, M. 2010. The response of interleukin-6 and soluble interleukin-6 receptor isoforms following intermittent high intensity and continuous moderate intensity cycling. Cell stress and chaperones - Ed.15. pp. 827-833.

Monteiro-Jonior, R., Maciel-Pinheiro, T., Mello, M., Silva, L., Terra, R., Careneiro, L., and Laks, J. 2018. Effect of Exercise on Inflammatory Profile of Older Persons: Systemic Review and Meta-Analysis. J Phys Act Health, 15: 64-71

Gomez-Rubio, P., and Trapero, I. 2019. The Effects of Exercise on IL-6 Levels and Cognitive Performance in Patients with Schizophrenia. Disease. 7(11): 1-11

Fisher, C. 2006. Interleukin-6 in acute exercise and training: what is the biological relevance? Exercise Immunology Review - Ed.12. pp 6-33.

Kershaw EE and Flier JS. 2004. Adipose Tissue as an Endocrine Organ. The journal of Clinical Endocrinology \& Metabolism 89(6):2548-2556

Petersen, A., and Pedersen, B. 2005. The anti-inflammatory effect of exercise. J Appl Physiol. 98: 11541162 .

Pedersen, B.K., \& Febbraio, M.A., 2008. Muscle as an Endocrine Organ: Focus on Muscle-Derived Interleukin-6. Physiol Rev 88: 1379-1406; doi:10.1152/physrev.90100.2007.

Thiruvoipati, T., Kielhorn, C., and Armstrong, E. 2015. Peripheral arterial disease in patients with diabetes: Epidemiology, mechanisms, outcomes. World Journal of Diabetes-Ed. 6, 961-969.

Polen ZK, Joshi S. 2014. Comparison of Treadmill versus Cycle Ergometer Training on Functional Exercise Capacity in Normal Individuals. IJCRR. 6(20): 61-65.

Kilpatrick M, Little JP, Jung ME. High-Intensity Interval Training: A Review of Physiological and Psychological Responses. ACSM's Health and Fitness Journal. 2014 Sept; 18(5): 10-6

Ilyas EI., 2009. Olahraga Bagi Diabetisi. Dalam: Sidartawan Soegondo, Pradana Soewondo, dan Imam Subekti, 2009. Penatalaksanaan Diabetes Melitus Terpadu. Edisi 2. Cetakan ke-7. Jakarta: Fakultas Kedokteran Universitas Indonesia, halaman 73-74.

Cassidy S, Thoma C, Houghton D. High-Intensity Interval Training: A Review of Its Impact on Glucose Control and Cardiometabolic Health. Diabetologia. 2016 Sept 28; (16): (17p)

Eaton Stanley B, Eaton S Boyd. Physical Inactivity, Obesity, and Type 2 Diabetes: An Evolutionary Perspective. Research Quarterly for Exercise and Sport. 2017 Jan 27; (10): (9p)

Elias Da Silva D, Grande AJ, Roever L, et al. High-Intensity Interval Training in Patients with Type 2 Diabetes Mellitus: a Systematic Review. Current Atherosclerosis Reports. 2019 Feb 02; 21(8): (10p) 
Tanaka, T., Narazaki, M., dan Kishimoto, T. 2014. IL-6 in Inflammation, Immunity, and Disease. Cold Spring Harb Perspect Biol, pp 1-16.

Qu, D., Liu, J., Lau, C., and Huang, Y. 2014. IL-6 in diabetes and cardiovascular complication. British journal of Pharmacology-171, 3593-3603. 